ACCOUNT OF A CASE

or

\title{
CALCULUS IN THE BLADDER
}

REMOVED BY LITHOTRITY,

IN WHICH A COMMUNICATION EXISTED BETWEEN

THE BLADDER AND INTESTINE.

BY

\section{CHARLES HAWKINS,}

FELLOW OF THE ROYAL COLLEGE OF SURGEONS; VICE-PRESIDENT OF THE EOCIETY ; CONSULTING SURGEON TO QUEEN CHARLOTTE'S HOSPITAL; INSPECTOR OF ANATOMY, ETC.

Received May 11th, 1858.-Read June 22d, 1858.

I HAVE ventured to bring the following case before the Royal Medical and Chirurgical Society because $I$ believe it to be in some respects peculiar, and the operation having been followed by a successful result, it may induce those who may meet with similar cases to have recourse to the same means of giving relief. As far as I know, lithotrity has not been performed under like circumstances.

On July 14th, 1857, Sir Benjamin Brodie and myself were cousnlted by a gentleman, aged 55, suffering from all the symptoms of stone in the bladder in a most aggravated form. He was much worn by a constant desire to pass water, accompanied with very great pain ; the urine was alkaline, depositing much ropy mucus; his pulse was quick, and his appe- 
tite bad. His bladder was examined, and a stone readily detected.

The following history of his case is in his own words :

"It was in February 1855, I first discovered a substance about two inches in length, which I had passed with my water; it had a most offensive smell. I said nothing about it, although I was passing it every day, because it gave me no pain or inconvenience, until June in the same year, when I showed some of the matter to my ordinary medical attendant, who would scarcely believe that it came with my water. $\mathrm{He}$ ordered me some medicine, which in no way diminished the quantity I passed. I consulted the same gentleman again in the following November, when he felt satisfied that what I passed with my water was fæcal matter, and he told me that there must be an opening from the bladder into the bowel, he gave me little hope of being able to give me any relief. During the year 1856, I ceased to pass any of the substance, but early in this year the symptoms of disease of the bladder set in, and continued with great severity during the whole year. In the beginning of the year 1857, I saw two other surgeons in consultation, when an instrument was passed into the urethra, and one into the rectum at the same time. I suffered much pain from this examination, and afterwards passed blood from the rectum. These gentlemen came to the same conclusion as my own medical man, that an opening existed between the bladder and bowel; they both gave a most unfavorable opinion of my case, and thought that nothing could be done for my relief. It was not until I saw Sir B. Brodie and you that stone in the bladder was detected."

It wasdecided that, notwithstanding the history of the case, an attempt should be made to remove the stone, as the patient was sinking from the mischief it was causing in the bladder. But his general health was so much impaired and the absence of continued sleep for now upwards of a year had rendered him so very nervous, that I thought it unwise to commence any operation until I had made an attempt to 
-improve his state, and allay the irritability of his bladder: I advised him to return into the country, and to take some quinine and acid, and introduce into the rectum every night an opium suppository. He derived some benefit from this treatment, and the bladder-symptoms were a little abated. He returned to London on July 20th ; on the 25th, I performed the operation of lithotrity. The patient was anxious that he should be put under the influence of chloroform, and Dr. Snow administered it. I may state, in passing, that it is not my usual practice to have recourse to chloroform in lithotrity; I do so occasionally, on account of some special circumstances, but it is the exception, not the rule, in my practice. It is unnecessary to enter into my reasons for this on the present occasion, as I hope I may at some future period be permitted to bring before the Society my experience in this operation. The bladder held comfortably five or six ounces of water, a stone was readily seized, which was so large that the lithotrite could barely be opened sufficiently wide to grasp it; it was very soft, and gave way under the pressure of the finger. The patient bore the operation remarkably well, and soon began to pass fragments of triple phosphate; his bladder-symptoms were much relieved, and he continued to pass stone without any inconvenience till the 29 th.

On the 31st, I again operated (Dr. Snow giving chloroform); the fragments continued to pass easily, and he now slept for upwards of an hour without being disturbed.

On August 5th, I repeated the operation, and at the patient's request, without chloroform. He had found on the previous occasions that it was a long time before he recovered from its effects, remaining in a confused and an uncomfortable state of feeling for upwards of twelve hours. The operation was borne quite as well as it had been when chloroform had been used; the bladder held more water. I was able to do as much, and the patient complained of scarcely any pain, the fragments passed as easily as after the former operations, and all his symptoms continued to abate.

On the 12th, I operated again, with like success. On visiting him the next morning, I found him much depressed, 
with a quick and feeble pulse, cold skin, and some drowsiness. He had not been able to pass any water in the night and unfortunately had not sent for me; but he said that early in the morning his bowels had acted, since which he had been easy. Upon examining what had been passed by the bowels, I found a large quantity of urine mixed with a considerable quantity of blood: it was evident that some obstruction to the passage of the urine by the natural way had occurred that could not be overcome, and that the bladder had given way, I concluded, where the old opening had existed. I prescribed astringents, and ordered lumps of ice to be introduced into the rectum, and confined his diet to cold drinks. Mr. Cæsar Hawkins, who met me in consultation on this day, concurred in this treatment; it was continued for two or three days. Neither at this time, nor at any other when I examined the rectum with the finger, could I detect any opening into the bladder. For about twenty-four hours all the urine came by the rectum, it was then passed by the urethra, untinged with blood: and in forty-eight hours no blood was passed by the rectum. In four or five days he was quite as well as he was before the last operation, but he continued to pass some urine through the rectum.

Not considering it advisable to continue any operative proceedings at this time, he left London on the 20th, without any further examination of the bladder being made; his general health had much improved and the bladder-symptoms abated. I prescribed decoction of pareira brava and hyoscyamus.

The symptoms of stone however continuing, he returned to London on October 5th. On the 7th, I examined the bladder, which held six ounces of water well; stone was readily detected, which I crushed; he bore the operation remarkably well. On the 21 st, all the symptoms of stone were gone. I examined the bladder, and could not detect any; he was anxious to return home on business, and left London the next day. Towards the end of the year the symptoms of stone returned. On January 25th, 1858, he came to London again in excellent general health, but with unmistakable symptoms of stone in the bladder. 
On the 27th, I examined the bladder, at once seized a stone, and crushed it. From the fragments he passed I believed it to be a new formation.

On the 30th, I repeated the operation.

On February 2d, I examined the bladder, and could not detect any stone. The urine was quite healthy. He neither suffered pain nor inconvenience, slept nearly all night, and the next day he left London with directions to pass a gum catheter, and to well wash out the bladder with warm water daily, so as to prevent, if possible, fæcal matter lodging in the bladder, and again forming a nucleus for stone, as he had been passing fæcal matter with his water, from time to time, for the last three months, and on the last two occasions of my operating, fæcal matter passed through the catheter when I injected the bladder. I had given him the same directions when he left London before, but circumstances had prevented his following them, hence the new formation of stone.

Since his return home the patient has remained perfectly well. A few days ago I received the following note from him :

"I am very happy in being able to inform you that I continue quite well ; free from all pain. I am better than I have been for years. I pass my water very freely. I use the instrument every night. I have discovered once a considerable quantity of fæces ; once a small quantity; but at other times my water has been quite clear; never any blood." He ends his note with this laudable expression of gratitude for what surgery has done for him: "when I an dead, if my bladder or any other portion of my body will be of any use for the benefit of my fellow-creatures, it is at your service."

It is difficult to give an idea by weight of the size of the stone removed, as it consisted entirely of triple phosphate; but if all the detritus had heen collected it would have filled a three or four ounce bottle.- 
Dr. Ogle, of St. George's Hospital, who kindly examined it for me, gives the following account of it: "it was formed of the triple phosphate, having as a nucleus a number of little foliaceous-looking masses, of about one eighth to one fourth of an inch in size; after the addition of a little acid they were quite obviously seen to be vegetable in character, presenting numbers of vegetable cells in a good state of preservation."

From the foregoing history it is evident that at some period ulceration must have taken place in the bladder or bowel, most likely, in the first instance, in the latter, resulting in the communication, which existed previous to the symptoms of stone showing themselves; and as no fæcal matter passed with the urine for upwards of a year previous to the operation, it may be concluded that the opening had closed, and continued so until the occasion of the retention of urine, in the night of August 12th, when it was again opened.

It is not a little singular that so much mischief should have taken place, resulting in a communication between the bladder and intestine, occasioning so little inconvenience to the patient, for until he perceived the fæcal matter in his urine he experienced no inconvenience of any kind with reference to those parts.

Notwithstanding all that had taken place, and the very great irritability of the bladder that existed in this case, and I scarcely ever saw greater suffering, I never had a patient that was so little distressed by the operation, or passed through all its stages more satisfactorily, until the unfortunate occurrence of the 13th of August; and it is surprising that after the communication with the bowel again existed, the bladder was still able to retain between six and eight ounces of water, and bear without any ill effect the presence of the instrument, and the manipulations necessary for seizing and crushing the stone. 